\title{
Aesthetics of Transformation in the Artistic Architecture in the Light of Anamorphosis
}

\author{
د/ إيمان محمد عبده المعاز \\ دكتوراه فلسفة التربية النوعية \\ (تربية فنية _ تخصص تصميم ) \\ كلية التربية النوعية _ جامعة المنوفية \\ أخصائي تدريس تربية فنية بالتربية والتعليم
}

\author{
أ.د / زينب صبرة
}

\author{
أستاذ الأثغال الفتية \\ ورئيس قسم الأشغال الفنية والتراث الثعبي سابقاً \\ كلية التربية الفنية _ جامعة حلوان
}

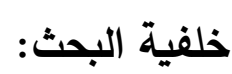

إن الفنون الحديثة علي تتوعها وتميزها ، وتعدد إتجاهاتها ومصادرها متشابهة في منطلقتها الأساسية تجمع بين إرادة التجديد والتحول الدائمين إستتاداً إلي واقع متغير، والفنون التشكيلية علي إختلاف مجالاته الفنيه فإنها تواكب التطوارت العلمية والتكنولوجية ، وتتسم بتفاعلها وتعايثها مع الإتجاهات التكنولوجية المختلفة ـ أي أن تلك المستويات تبدأ من الأبسط دائماً وبطرق متتوعة ومختلفة الأساليب ، ولكنها تتبع قواعد وقوانين النمو للعالم المادي التي تتنمى إليه للوصول إلى مستويات أكثر تعقيداً. ولقد أدى التطور الهائل في العلوم والتكنولوجيا الذى يشهده هذا العصر في كل المجالات إلى إثراء الرؤية الفنية وتعدد الخبرات حيث ذابت الفروق الحادة بين مختلف مجالات وتخصصات الفن التثكيلي ، وفى العصر الحديث نلاحظ هذا الترابط وثيقاً جداً في العديد من الإتجاهات الفنية الحديثة ،"وقد أشار الفنان المصمم جوزيف هوفمان(•) Josef Hoffmann (1870 - 1956) إلى أنه كثيرا من الفنانين قد صرحوا بأن الاكتشافات العلمية أوضحت لهم الرؤية ، وأبدت اتجاهاتهم الفنية وفتحت لهم آفاقاً جديدة ".(1) ومن ثم فقد تعددت الاتجاهات والحركات الفنية التي كان دافعها وهدفها الأساسي السعي لتقويم وتطوير الأعمال الفنية في جميع المجالات

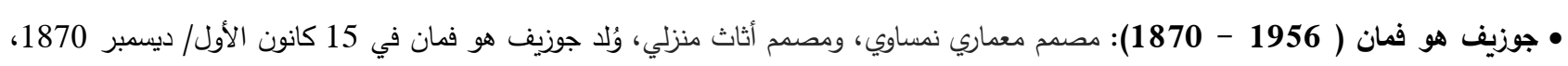


الفنية "Vienna Secession 1- مختار العطار 1992 : "الفن والحداثة بين الأمس واليوم" ، دراسات في نقد الفنون الجميلة (1) ، الهيئة المصرية العامة للكتاب ، القاهرة ، ص20. 


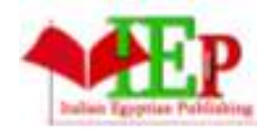

ISSN: $2735-4342$
INTERNATIONAL JOURNAL OF

MULTIDISCIPLINARY STUDIES IN ART AND

TECHNOLOGY

الفنية التثكيلية ومدي تأثر تلك المجالات بتلك التيارات الفنية ، أما توماس أكوينسThomas Aquinas(2) فقد أكد علي أن العلاقة بين الجمال وعلم الرياضيات فلا يوجد شيء في الطبيعة إلا ويمتاز بتناسقه باعثاً على السرور ، ويمكن القول بأن الإنجازات العلمية الدتعاقبة كان لها تأثير مباشر على العديد من مجالات الفن التثكيلي " فقد أصبح من خصائص هذا العصر التصارع الغريب من أجل تطبيق نتائج الأبحاث العلمية في شتي مجالات الحياة ".(3) وكان لظهور العديد من تلك النظريات العلمية أثر بالغ في ظهور ألوان جديدة من ضمن هذه الألوان الأنامورفوسيس AnamorPhoses وهو " إعادة صياغة التكوين التثكيلي برؤية منظورية من خلال الدفهوم الرياضي للنسب التثكيلية ، وتحويليها إلى تكوين غير منتظم في الخطوط والإتجاهات،

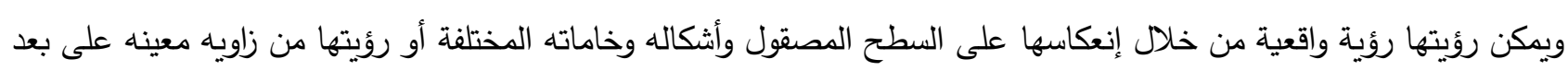

معين"(4 )، ويعتمد الأنامورفوسيس AnamorPhoses على تحويل المنظور بطريقة رياضية مخصصه لنوع المرايا المستخدمة سواء كانت أسطوانية أو هرمية أو مخروطية ، فكل مرآه ولها طريقتها الخاصة بها في تحويل المنظور باستخدام قانون الانعكاس ، وهذا هو المقصود" بالمفهوم الرياضي " الذي يعتمد عليه الأناموفوسيس .
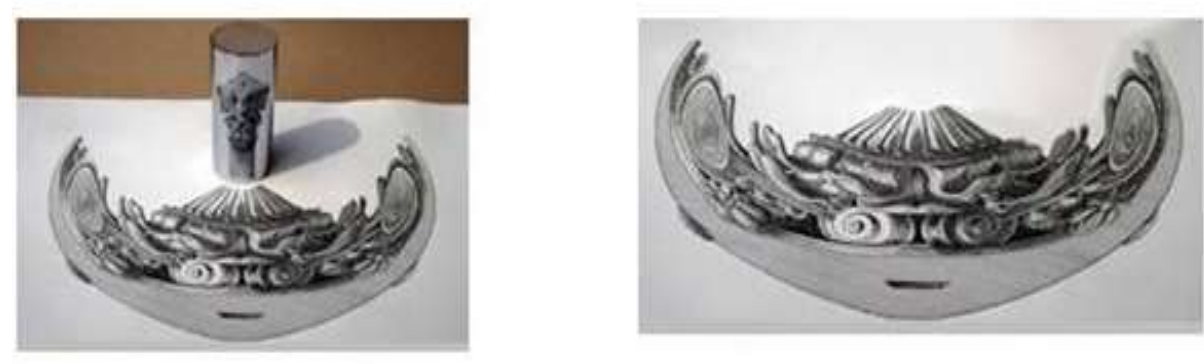

شكل ( 1) صورة ما قبل وضع المرآة الأسطوانية ، وبعد وضع المرأة الأسطوانية تتضح رؤيه الثكل (5 )

والأنامورفوسيس هو ذلك الفعل الذي يجعل الأثياء أو الأثكال أو الألوان ترى أو تدرك بطريقة خادعه و مغايرة ، لماهيتيا

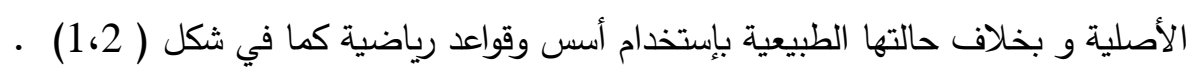

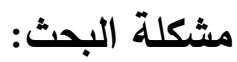

2 توماس اكويناس ( 1274 - Thomas Aquinas(1225) : كان كاهن دومينيكان وفيلسوف ولاهوتي إيطالي من الكنيسة الكاثوليكية ويوجد له

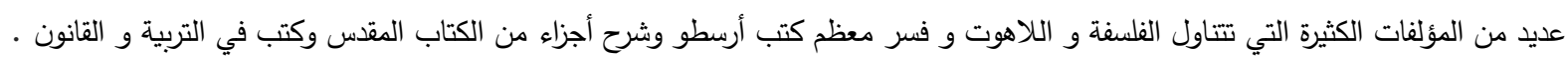

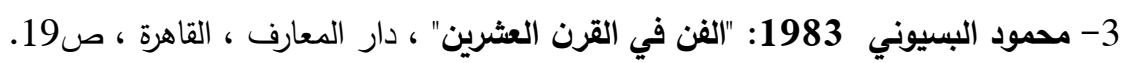
/https://mbnart.wordpress.com/83-2 ${ }^{4}$ 5 نفس المرجع السابق 
نتيجة التطور العلمي الهائل والمستمر في شتي ميادين المعرفة العلمية والتربوية ومنها مجالي الأشغال الفنية و التصميم ، وإستثمار هذا التطور وخاصة أن ممارس الفن دائماً ما يواجه مشكلة البحث عن المرجعيات الجديدة والخلفيات العلمية لتطبيقها نظرياً وعملياً ، لذا وجب الإعتماد على ذلك التطور العلمي ومن هذا المنطلق إتجه البحث إلى دراسة جماليات التحول في بنية المشغولة الفنية في ضوء الأنامورفوسيس والإستفادة منه في تتفيذ ذلك عملياً ، ومن هنا تتحدد المشكلة في التساؤل التالي : - - هل يمكن إستحداث مشغولة فنية وفقاً لجماليات التحول في ضوء الأنامورفوسيس ؟ فرض البحث : تفترض الباحثة ما يلي :-

ـ الإستفادة من الأنامورفوسيس القائم علي جماليات التحول كمخل لمنطلقات تجريبية جديدة يكمن الإعتماد عليها في تدريس مادتي الأشغال الفنية و التصميم • هدف البحث :- - إستحداث مشغولة فنية معاصرة قائمة على جماليات التحول في ضوء الأنامورفوسيس .



1- يعتبر هذا البحث إثراء لمجالي الأشغال الفنية والتصميم بمداخل للتدريس تعتمد علي جماليات التحول في ضوء الأنامورفوسيس . 2- إضافة دداخل فكرية جديدة لدراسات الأشغال الفنية و التصميم التي تستتد إلي العلوم الحديثة . حدود البحث :1- يقتصر البحث على دراسة وتحليل تقنيات الأنامورفوسيس من خلال عينة مختارة لأعمال الفنانين الذين إعتمد أعمالهم علي ·ماليات التحول في ضوء الأنامورفوسيس 2- تتفيذ مشغولة فنية معاصرة قائمة علي جماليات التحول وتستتد إلي المفهوم الرياضي والنظرية العلمية في ضوء

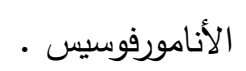
منهجية البحث :يتبع البحث المنهجين التحليلي والتجربي لتحقيق أهداف البحث ويتم ذلك من خلال الإطارات التالية :- ملات 
أولاً : الإطار النظري ويتضمن هذا الإطار ما يلى :

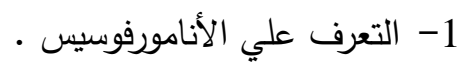

2- دراسة جماليات الأنامورفوسيس القائم علي الدفهوم الرياضي ، وأهم فناني هذا الإتجاه .

3- دراسة جماليات الأنامورفوسيس المستند إلي النظرية العلمية ، وأهم فناني هذا الإتجاه . 4- دراسة جماليات الأنامورفوسيس المعتمد علي الإضاءة الحديثة .

ثانياً : الإطار العملي ويتضمن هذا الإطار ما يلى : الإستفادة من معطيات التحليلات السابقة في إجراء تجربة تطبيقية تعتد علي ما تم التوصل إلمانيه من خلال نتائج الدارسة النظرية والتحليلية كمدخل تجريبي في مجال الأشغال الفنية في ضوء الأنامورفوسيس .

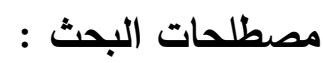

\section{: anamorphosis الأنامورفوسيس :}

هو " إعادة صياغة التكوين التثكيلي برؤية منظورية من خلال المفهوم الرياضي للنسب التثكيلية ، وتحويليها إلى تكوين غير منتظم في الخطوط والاتجاهات، ويمكن رؤيتها رؤية واقعية من خلال انعكاسها على السطح المصقول وأثكاله وخاماته المختلفة أو رؤيتها من زاويه معينه على بعد معين" (6 ).

\section{قانون الانعكاس" : The Law of Reflection} القانون الأول : زاوية السقوط = زاوية الانعكاس.

القانون الثاني :الثعاع الضوئي الساقط والثعاع الضوئي المنعكس والعمود المقام من نقطة السطح العاكس تقع جميعها في مستوى واحد عمودي على السطح العاكس ، وأن الثعاع الضوئي الذى يسطط عموديًا على السطح العاكس ينعكس على نفسه لأن زاويتي السقوط والانعكاس تساوى صفرًا ، و ينعكس الضوء على الأجسام الملساء وفقاً لزاوية سقوطه عليها .


هو أحد فروع علم الميكانيك الذي يصف مفهوم الحركة الفيزيائي للأجسام بدون أى إعتبار للكتل أو القوى التي تسبب الحركة . (الإنكسار المزدوج " Double refraction"

1 /https://mbnart.wordpress.com/83-2 ${ }^{6}$

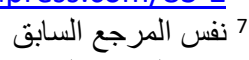
8 نفس المرجع السابق 
يمكن لبعض المواد الثفافة في الطبيعة ان تحدث انكسارا مزدوجا لجسم ما بحيث تظهر له صورتان في الوقت نفسه هذه العملية تسمى الانكسار المزدوج.

أولاً: الإطار النظري للبحث :1_ تعربف فن الأنامورفوسيس

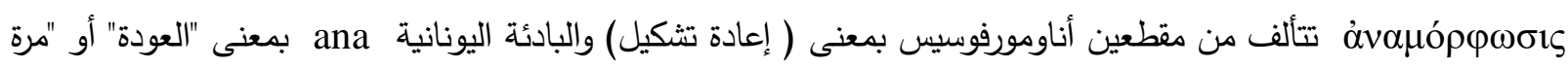
أخرى" ، وكلمة morphe التي تعني "الثكل" أو "التشكل" لصورة بصرية متغيرة الأبعاد وهي ترجمة واضحة لعملية رياضية تسمى التحول التقريبى للأشكال المادية ، وتعريف الأناموفوسيس من حيث إتجاه البحث الحالي هو إسقاط مشوة أو منظور يتطلب من المشاهد لإستخدام أجهزة خاصة أو إتخاذ وجهة نظر محددة لإعادة تثكيل الصورة , فهو يعتمد علي إتجاه ورؤية العمل الفني

\section{2_ جماليات الأنامورفوسيس القائم علي المفهوم الرياضي :}

_ تفسير الأنامورفوسيس تبعاً للمفهوم الرياضي وفق لنيسرون Niceron: ويتضح من شكل (3) و عند النظر إلي الأنامورفوسيس من وجهة نظر Niçeron لوحة متحولة وفقًا لقواعد منظور محددة ، وإستعادتها إلى التتسيق العادي إما عن طريق عرضها من زاوية معينة ، أو عن طريق إعادة تشكيلها كما نشر في كتيب إرشادي لفن الرسم المحول يحتوي على توجيهات لتحويل الصور العادية إلى فن متحول و يجب رؤية أي تحول جانبي من زاوية عرض مثالية ، وهي الزاوية التي سيعود فيها التحول الظاهر إلى شكله الأولي والواقعي وغير الممتد للإنعكاس الأمامي للشكل المتحول وضع مائل للشكل المتحول .

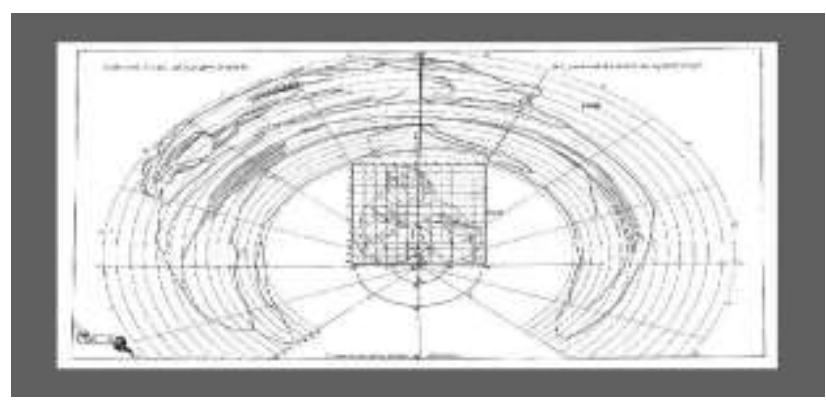

_ جان نايسرون: (5 يوليو 1613 - 22 سبتمبر 1646) عالم رياضيات فرنسيًا ، ورسامًا للفن المشوه ، حيث كان رائدًا في كتاباته عن المنظور الغريب La Perspective Curieuse 10)10( Sánchez-Reyes, Javier; Chacón, Jesús M. (August 1, 2016). "Anamorphic Free-Form Deformation". Computer Aided Geometric Design. 46: 30-42. doi:10.1016/j.cagd.2016.06.002. 


$$
\text { شكل ( 2) طريقة توضيح نايسرون لمتشوه الأسطواني ( } 11 \text { ) }
$$

ويتم إنشاء صور بصرية مشوبة بإستخدام الثبكات، و للقيام بذلك يتم رسم شبكة مربعة فارغة ، ويتم إعادة رسم هذه الثبكة في شبكة مشوهة إعتماداً على التثكل" التحول " المراد إنشاؤه في حالة تشوه المنظور ، تُظهر الشبكة الجديدة خصائص رسم المنظور ، " يفتح التثوه الأسطواني مسارًا بزاوية 360 درجة حول المرآة والذي يتطلب زاوية رؤية بمقدار 90 درجة تقريبًا في إرتفاع المساحة (من قاعدة الأسطوانة إلى منظر الطائرة) ، للوصول إلى وجهة النظر المثالية" (12) . ب _ الفنان القائمه أعماله علي المفهوم الرياضي بإستخدام ( الأسطوانة ) : الفنان جونتي هورويتز Jonty Hurwitz : وهو فنان يخلق أعمالاً فنية مستوحاة علمياً ومنحوتات بصرية مشوهة لأصغر شكل إنساني تم إنثاؤه باستخدام تقنية النانو" (13) ، أنتج هورويتز مجموعة من الأعمال باستخدام كل من الثكل المائل (المنظور ) والثكل القطني (المرآة) ، وإكتثف خيط رفيع يفصل بين الفن والعلم في أعماله الفنية وأنه يمكن إستخدام العلم بإعتباره الفرشاه الفنية ، وكلاً من منحوتاته هي دراسة عن الفيزياء من الكيفية التي ننظر بها إلي الفضاء ، وجوهر أعماله الفنية هي نتيجة لكتلة من التكنولوجيا والإبداع البشري ودمج العلم بالفن كما في الأشكال التالية .

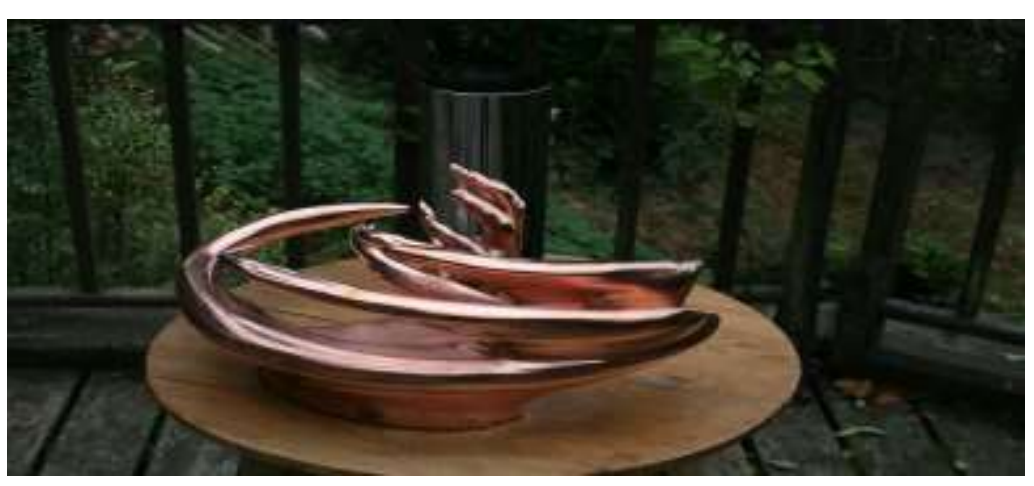

$$
\text { شكل (3) العمل يسمي أيدي الأمهات (14) }
$$

http://figuresambigues.free.fr/ArticlesTheorie/5-ambigu-orientations.html\#axzz6mdCShxvV ${ }^{11}$ 12 نفس المرجع السابق . جونتي هورويتز : " من مو اليد 2 سبتمبر 1969 في جو هانسبرغ ، وتوفي 24 مارس 2012" . https://en.wikipedia.org/wiki/Jonty Hurwitz ${ }^{13}$ https://www.boredpanda.com/anamorphic-sculptures-jonty- 14 hurwitz/?utm source=google\&utm medium=organic\&utm campaign=organic 
وتجسيد أيدي الأمهات ، فالأيدي هي التي تربي وتتحمل كل شئ فهي يد التتشئة ويد الطبيعة ، وتظهر تلك المنحوتات من خلال لغة الترومبولاي "trompe l'oeil" فهي منحوتات بصرية مشوهة لا تكثف عن نفسها إلا عندما تواجه أسطوانة عاكسة أو أي سطح عاكس كما في الثكل السابق، ويتم تحول العمل الفني المتوقع في منتصف العمد ويتعين من خلال الأسطوانة لإدراك الكائن الكامل الذي يمكن التعرف عليه في النهاية ، ويتقاطع العمل مع مجالات العلوم والفن ، والترومبولاي " وهي تقنية فنية تستخدم صورًا واقعية لخلق الوهم البصري بأن الكائنات المصورة موجودة في نظام ثلاثي الأبعاد ، والمنظور القسري هو وهم قابل للمقارنة في العمارة" (15 ) م

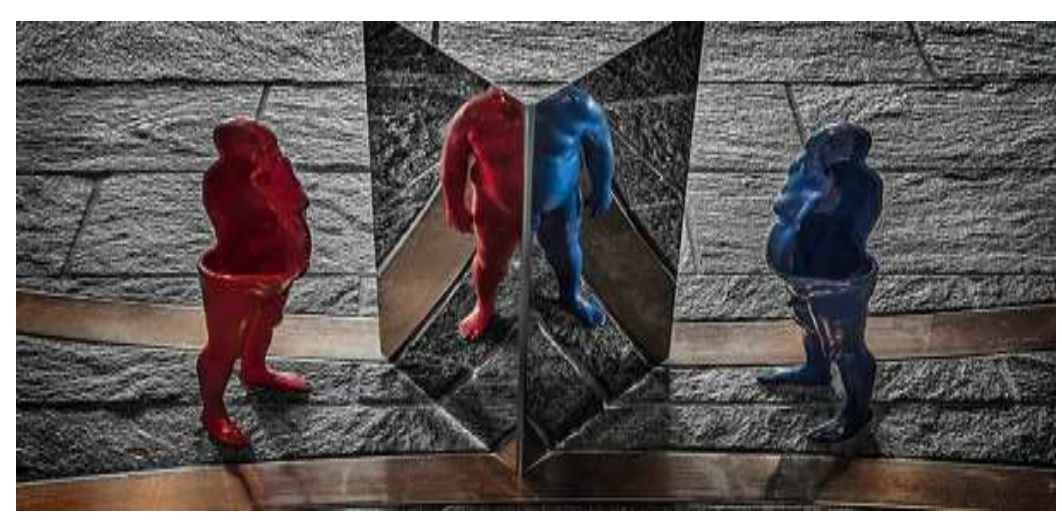

شكل (4) يوضح تناول أخر للفنان نحت لنصف شخص وعند وضع اللوح العاكس يري الثخص كاملاً ( 16 )، ودائمًا ما يمزج Jonty Hurwitz " بالتقريب بين الفن والفيزياء و يأخذ سياق الإدراك الإنساني كنقطة إنطلاق لعلم الجمال لسد الفجوة بين الفني والعلمي ، وتمر كل قطعة فنية بأشهر من التحضير ، حتى يجد المظهر الصحيح وتجسيدًا للصيغ المحسبة و بإستخدام مواد مختلفة مثل Perspex والصلب والراتتج والمسحوق والنحاس والاكريليك ، ويجعل Hurwitz كل عمل من التحديات الهندسية والفنية " ( 17 ) ( _ جماليات الأنامورفوسيس القائم علي المفهوم الرباضي:

https://en.wikipedia.org/wiki/Trompe-l\%27\%C5\%93il ${ }^{15}$ https://www.boredpanda.com/anamorphic-sculptures-jonty- ${ }^{16}$ hurwitz/?utm source=google\&utm medium=organic\&utm campaign=organic 
ـ الرؤية البصرية من خلال أسلوب الفنان جونتي هورويتز : تتحقق الرؤية بإتباع الرؤية الواقعية للمنحوتات من خلال إنعكاسها علي السطح المصقول "المرآة" أو رؤيتها من زاوية معينة من علي بعد معين ، ويتم التخطيط لتلك الأعمال وتحويلها رقياً من خلال إستخدام الرياضيات بالإستعانه بأدوات البرمجيات” 3d“.

ـ جماليات التحول في تنفيذ أعمال الفنان جونتي الفنية : إعتمد الفنان علي إنثاء منحوتات بصرية متحوله من خلال تخطيط منظوري مرتبط بقوانين فيزيائية ورياضية ، قد إعتمد فيها الفنان علي دمج الفن والعلم والتكنولوجيا والمفاهيم الجديدة ورائهما معتمداً في ذلك علي الأنامورفوسيس .

ـ القيم الجمالية المتحولة داخل أعمال الفنان جونتي الفنية : . يحول الفنان الصورة البصرية المحولة إلي شكل يدرك حسياً محدثاً إتحاداً مفاجئاً بالإندماج في لحظة الرؤية الفنية للعمل المحول حين الوقوف في زاوية رؤية معينة وإتجاه معين فتتضح رؤية

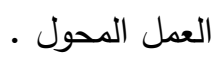

\section{3 3 : جماليات الأنامورفوسيس القائم علي النظرية العلمية :}

أ ـ قانون الإنعكاس : لجعل الصورة البصرية المحولة تبدو واضحة عندما تتعكس على أي سطح ما ، فإن الفيزياء الوحيدة التي تحتاجها هي قانون الإنعكاس، يثير قانون الإنعكاس إلى أنه إذا إصطدم شعاع من الضوء بمرآة بزاوية مقاسة من خط عمودي على المرآة ، فإن شعاع الضوء المنعكس سيخرج من المرآة بنفس الزاوية.

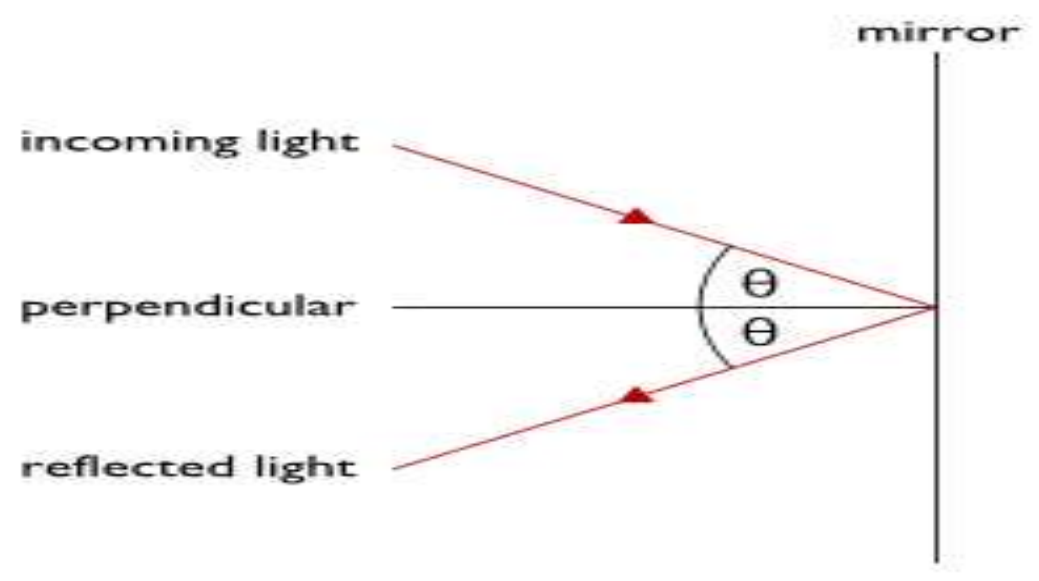




$$
\text { شكل (5) حالة بسيطة لقانون الانعكاس حيث تكون المرآة مسطحة ( } 18 \text { ) }
$$

تخلق الإنعكاسات من المرايا المسطحة أوهام بصرية، تبدو وكأنها نافذة على عالم الثري دي على جانبها الآخر ، ومع ذلك فإن كل شعاع من الضوء يبدو أنه قادم من الجانب الآخر ويأتي في الواقع من نفس الجانب الذي نقف عليه ، ولكنه ينحني فقط عند الزوايا التي يمكننا حسابها بإستخدام قانون الإزنعكاس ، فقد جاء الضوء في الواقع من نقطة ما على جانباً من المرآة ، وضرب المرآة بزاوية ما وإنعكس على الررآة بنفس الزاوية ، وهذا ما يحقق قانون الإنعكاس الأول ( زاوية السقوط = زاوية الإنعكاس) . ب _ زوايا الإنعكاس:1_ المعتمدة علي الإنعكاس في الإتجاه الأمامي :

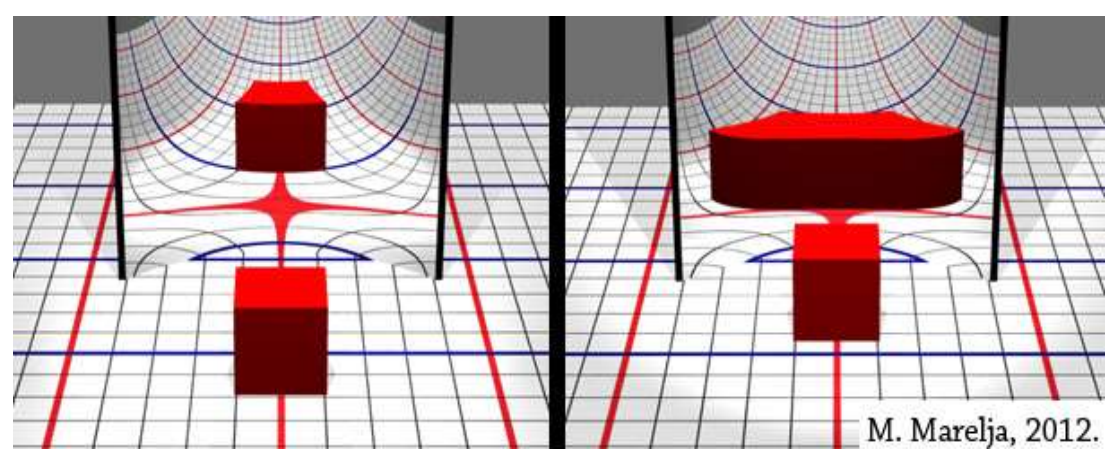

$$
\text { شكل (6) يوضح كيفية إنعكاس للثكل في الإتجاه الأمامي (19 ) }
$$

للإنعكاس على الجانب المقعر من المرآة الأسطوانية المعتمدة علي الإنعكاس في الإتجاه الأمامي توضح الصورة أعلاه محاكاة المستوى الداعم المغطى بنوع من شبكة الإحداثيات، ويرى كيف يتحول الجانب الأمامي والخلفي للمكعب وينحرفان بثكل مختلف في مساحة الصورة بسبب مسافاتهما المختلفة عن المرآة .

ـ ـ الفنان القائمة أعماله علي النظريـة العلمية بإستخدام الإنعكاس في الإتجاه الأمامي: الفنان الفرنسي برنارد براس Bernard Pras : إستخدم الأنامورفوسيس المثبت لإحداث صورة بصرية محولة من كائنات عشوائية عبارة عن تثبيتات من كائنات عشوائية ، وهي شكل من أشكال الفن الذي يحول فيه الفنانون الأشياء العشوائية إلى https://www.antoniosiber.org/marko mareljas anamorphosis en.html ${ }^{19}$ 
صور دقيقة وجيدة التتسيق لا يمكن رؤيتها إلا من خلال أجهزة خاصة أو من زاوية معينة معتمدة علي الإنعكاس في الإتجاه

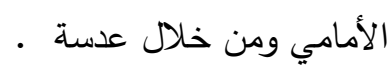

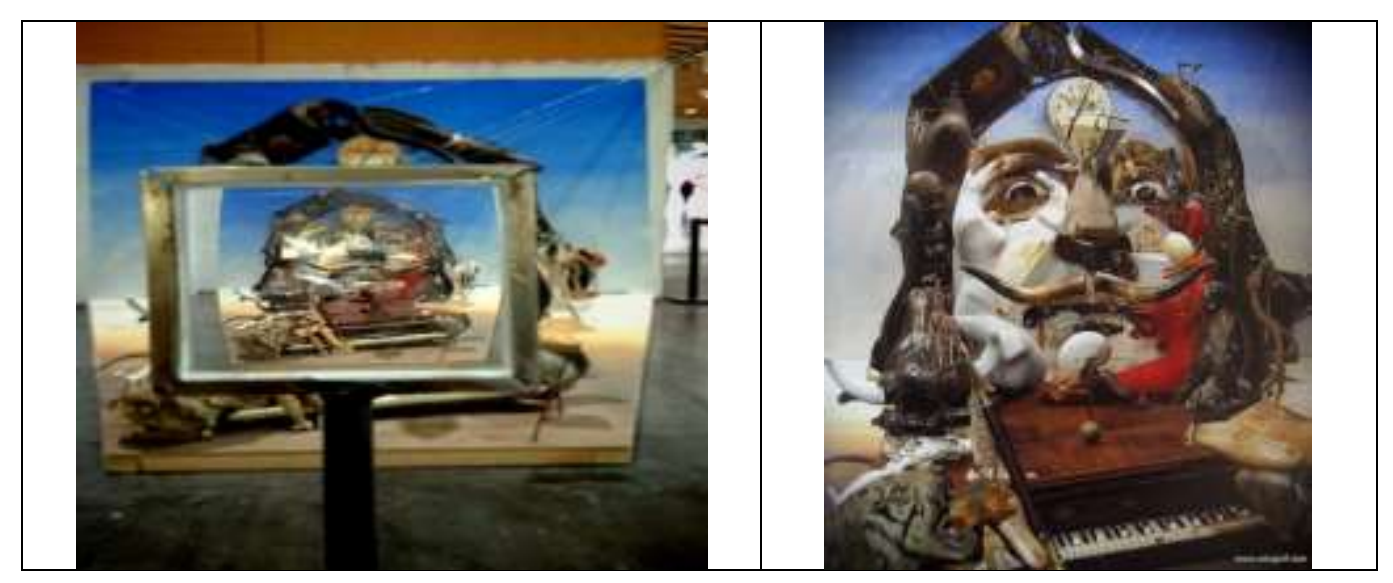

شكل (7) توضح مراحل العمل بإستخدام عدسة في الإتجاه الأمامي تتضح الرؤية للعمل(20)

يستخدم الفنان برنارد مجموعة واسعة من المواد المختلفة لبناء أعماله الفنية وعندما تنظر إلى التركيبات من الزاوية

الأمامية ، كل تلك الأشياء الغريبة المكونات تأتي في نهاية المطاف معاً وتكون العمل الفني بشكل مترابط، ويرتب “برنارد” المهملات والمخلفات فى شكل محدد لتوضيح صورة ما، ثم يضع كاميرته فى زاوية محددة جيداً مع إختيار مكان رؤية العمل بواسطة عدسة أمامية ، بحيث تدمج الأشياء مع غيرها فتظهر اللوحة المراد توضيحها للمشاهدين للعمل فنري التحول لرؤية تفاصيل العمل .

20 برنارد براس فنان فرنسى: ولد فى عام 1952 فى جنوب غرب باريس، وبعد أن أخذ الرسم هواية له لأكثر من 20 عاماً، عمل كنحات فى عام 1997،

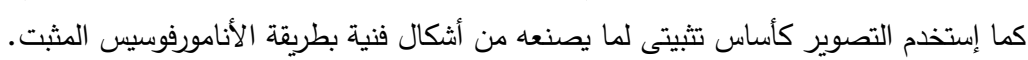
https://www.yelp.fr/biz_photos/art-up-lille?select=r7SjytGVZSR9yF_HjDAyqA 


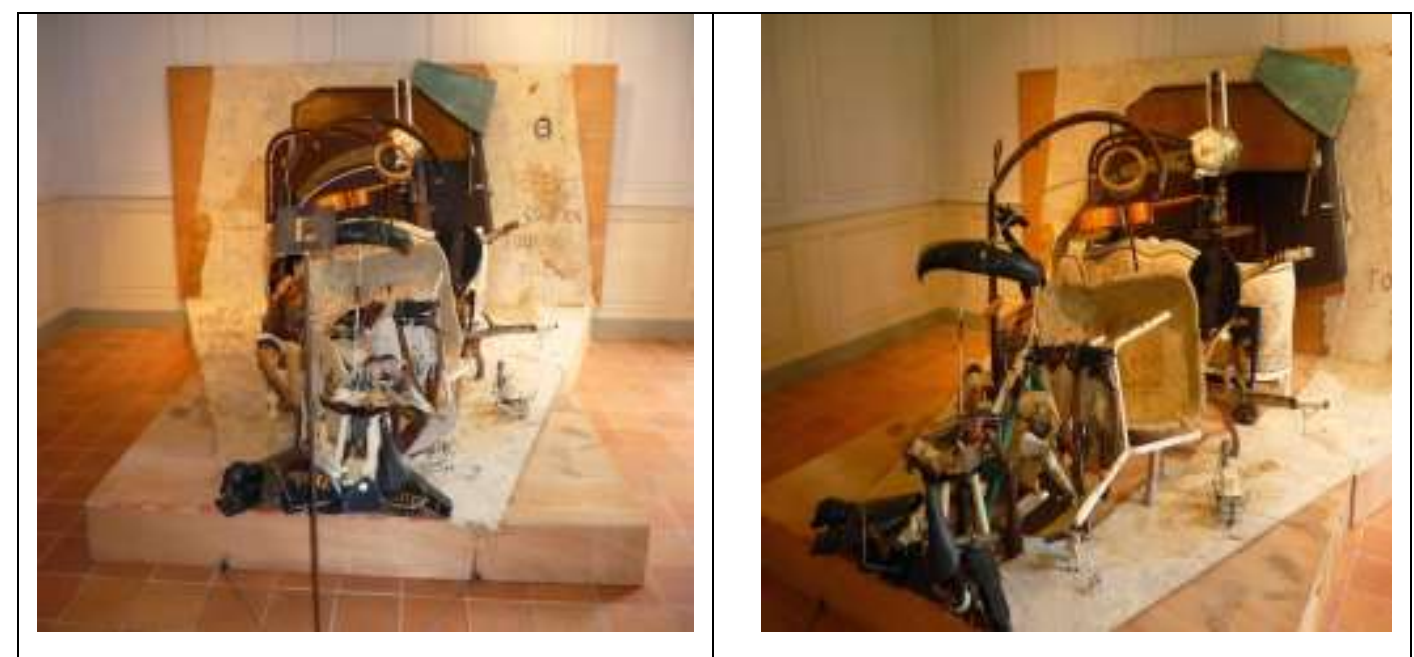

شكل (8) لفرديناند شوفال " ساعي بريد فرنسي" مكونات العمل من إتجاه جانبي وأمامي للعمل والرؤية بواسطة العدسة (21 )

جماليات التحول للأناموففوسيس القائم علي النظرية العلمية بإستخدام الإنعكاس في الإتجاه الأمامي:

أ. تعكس الثورة التكنولوجيا الجديدة الإنتقال من العلم للفن وإحداث نقلة في تغيير الرؤية الفنية .

ب. الإحساس بالتحرر الثكلي ، وتكثيف القوي التعبيرية والثكلية يقوي الإحساس الجمالي . ج. الطريقة اللا مألوفة في تتاول مادة العمل تأسر المتلقي وتكون أكثر إثارة وجاذبية من الوجهة الجمالية وتستحوذ علي إنتباه المتلقي لزمن أطول.

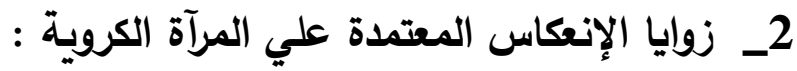
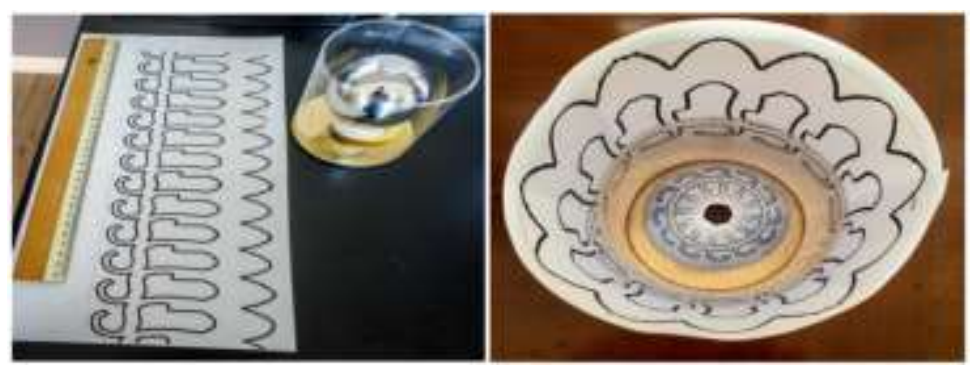

شكل (9) صور بصرية محولة كاتوبتريك لا يمكن رؤيتها إلا من دون تحول بمساعدة المرآة(22).

/https://mymodernmet.com/bernard-pras-ferdinand-cheval ${ }^{21}$ https://community.wolfram.com/groups/-/m/t/1646795 22

توماس ميديكس:ولد في14مايو 1727م - وتوفي في 2 أغطس 1788م ، فهو رسامًا إنجليزيًا للصور الثخصية والمناظر الطبيعية. 
_ _الفنان القائمة أعماله علي النظرية العلمية بإستخذام الإنعكاس المعتمد علي المرآة

الفنان توماس ميديكس Thomas Medix : هو فنان نمساوي يقدم نحت محول في شكل معاصر ، "و يتم إستخدام لوح زجاج ملون معلق كثاشة لرسم خرائط الإنقاط الخلفي، وبذلك يمزج التصوير الملون والموجز لخلية التي تظهر من خلال قطعة الزجاج الملون مع الرسوم المتحركة الرقمية ، ويبلغ قطر الإطار المعدني الدائري 1.5 متر ويضع قطعة من الزجاج الملون بين لوحين زجاجيين للسلامة في الجزء الخلفي، ويتم تركيب ما يسمى بفيلم الإسقاط المجسم الثفاف للحفاظ على الطابع الثفاف للنحت و يجعله مناسبًا للإسقاطات، ومن أجل توزيع الضوء بشكل متساوي على القرص تم إنشاء جهازين للعرض خلف النحت" (23) والعمل تم إنشائه عام 2018 بإسم "INTERCELLA
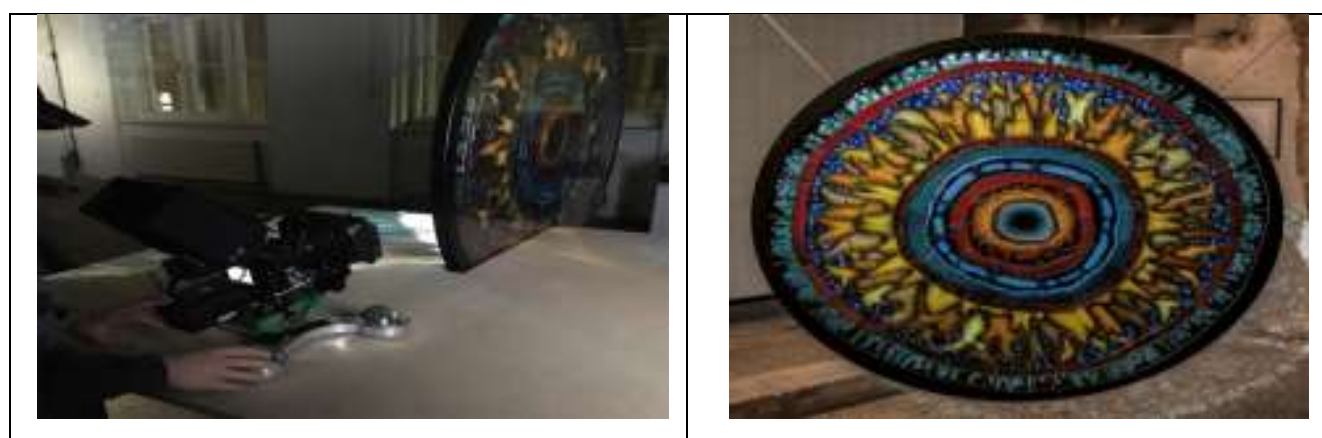

شكل (10) يوضح العمل أثناء العرض معتمدة علي المرآة الكروية بتسليط الضوء يتم التفاعل داخل العمل ويري

كذلك (24)النحت لمحطة مترو EXPO2020، "وتم إنشاء النحت في دبي، وسيتم بناء المحطة خلال السنوات القادمة ويظهر شعار EXPO2020 المخفي كل زاوية 90 درجة عند تدوير القطعة المحولة، ولهذا يتم نشر ما يقرب من 1000 قطعة زجاجية مرسومة باليد ومقطعة يدويًا على أكثر من 100 شريط زجاجي فارغ، وتم إنثاء الأجزاء الزجاجية بتقنيات مماثلة تستخدم لنوافذ

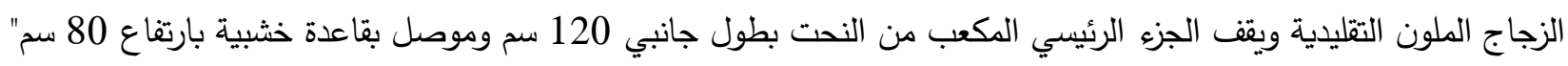




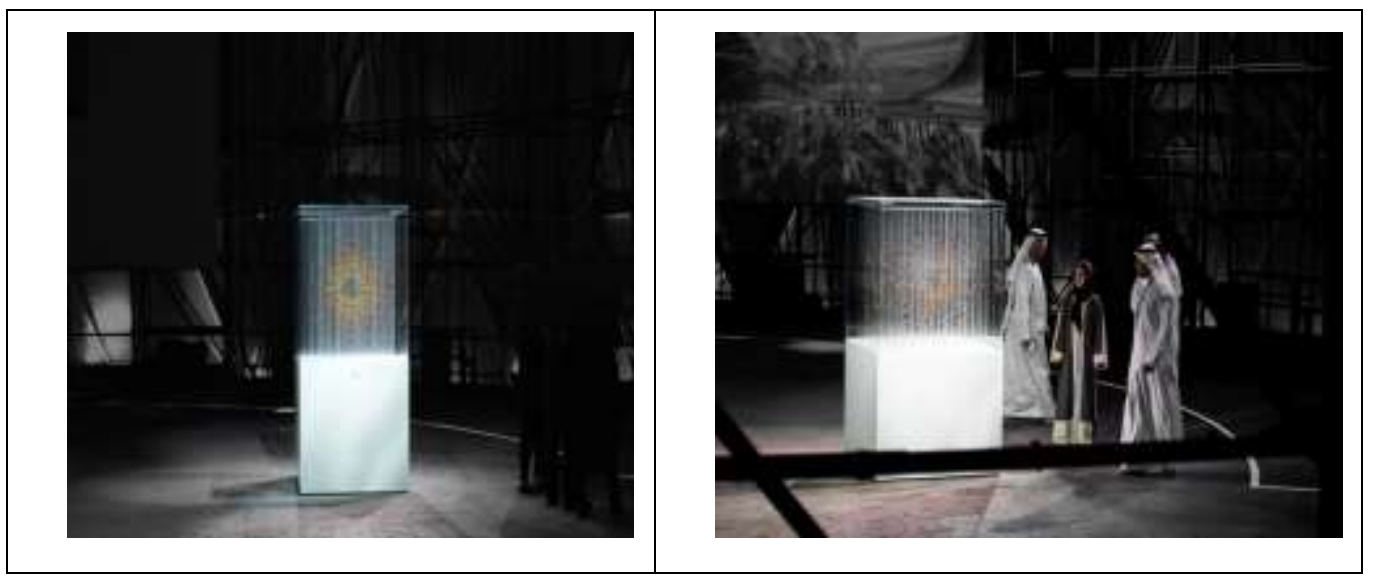

\section{شكل (11) يوضح العمل داخل المحطة مازالت تحت الإنشاء معتمدة علي المرآة الكروية26}

ـ جماليات التحول للأنامورفوسيس القائم علي النظرية العلمية بإستخدام الإنعكاس علي المرآة الكروية : أ.تميز الأعمال بمنطق كلي يحكم أجزاء التخطيط وإمتزاج القاعدة الرياضية لرؤية وخيال الفنان ب. تكتسب أعماله الفنية قيمة جمالية كالتتاقض بين الوضوح والغموض والتردد بين الإتزان والحركة. ج. إستخدام الألوان داخل الأعمال في كامل وضوحها وشفافيتها ، مما يحدث الألفة والفراده تجذب المشاهد نحو العمل ، ليصبح

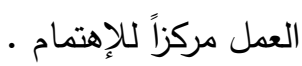

\section{لبعاً: جماليات الأناموفوسيس المعتمد علي الإضاءة الحديثة :}

الأناموفوسيس " بإستخدام كلاً من الضوء والظل وبإنشاء كائنات مفردة أو متعددة ووضعها فيما يتعلق بمصدر ضوء واحد، وبالتالي يتألف العمل الفني الكامل من كل من المادية (الأجسام الصلبة) وغير المادية (الضوء أو الظل) لإحداث الوهم أثناء رؤية العمل من خلال الإضاءة، والأنوار والظلال أمثلة أصلية على صورة بصرية محولة "(27 ). _ أعمال الفنانين القائمة علي الإضاءة الحديثة 1 الفنانة كومي ياماشيتا Yamashita Kumi) ) : " هي رائدة هذا الإتجاه ، والفلسفة 
التي تعتد عليها الفنانة في نحتها لأعمالها الفنية وهي " النحت بإستخدام كلاً من الضوء والظل، وتقوم ببناء كائنات مفردة أو

متعددة وتضعها فيما يتعلق بمصدر ضوء واحد " (28)

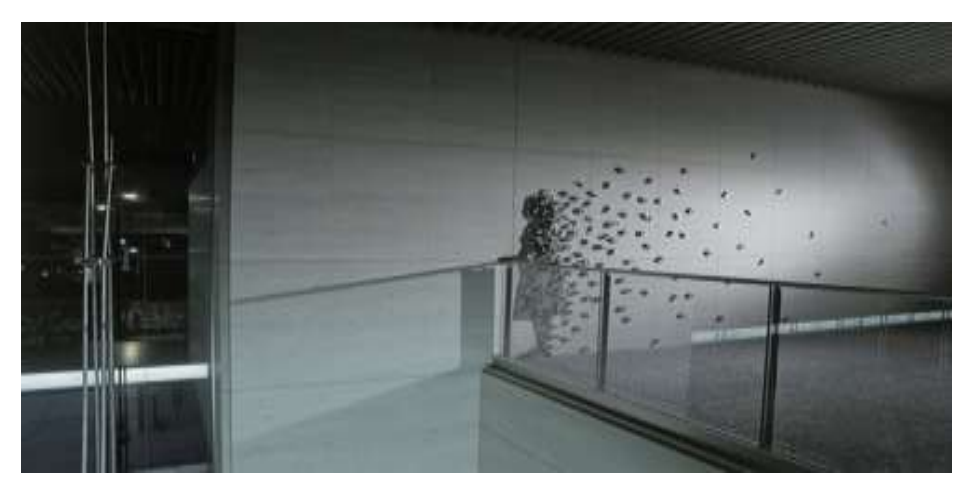

شكل (12) من زاوية رؤية عن بعد للعمل(29)، أرقام الألومنيوم مصدر ضوء واحد، الظل .

تحليل العمل " الزاوية والخيال هما جوهر عمل ياماشيتا وتربط الخيال "الأشياء العادية" بالظلال في العالم غير الواقعي، والزاوية هي النقطة الأساسية لتحقيق هذا الاتصال في العالم المادي، والصورة تدل علي سيدة تقف في البلاكون، والظلال التي أنثأتها الفنانه هي تدل علي أنها شخصية حقيقية تقف " (30)



شكل (13) يوضح قطع لوحة الألومنيوم ، مصدر ضوء واحد ، الظل،2005

مجموعة دائعة(31 Stellar Place Sapporo JR Tower ، هوكايدو، اليابان CLOUDS

والصورة الجانبية زوجان ظلان يبحثان عن مأوى من العناصر ونحت قطعة من الألومنيوم على شكل سحابة، نفس السحابة التي تدعو الأثكال المادية للزوجين إلى الوجود ، فإن أعمالها معقدة ودقيقة من الناحية التتنية، ومع ذلك تظل بشرية بشكل عميق، وتحدث الهدف الأساسي منها وهو الوهم "التحول " . 


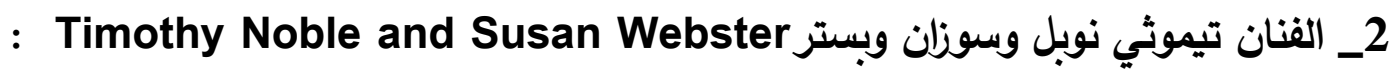

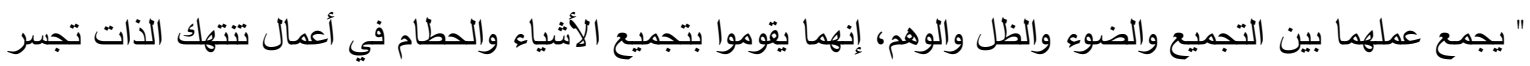
حقيقتين للوهلة الأولى، ولكننا سرعان ما نكتشف أن الأكوام هي في الواقع تركيبات دقيقة تلقي ظلالاً رمزية واضحة تحت الضوء الموجه، والصور الظلية التي نراها هي صور شخصية بارعة، وقام الفنانون بتجميع قطع من الأثاث المكسور، والسلالم، والصناديق، والسلع المهملة ويحولون هذه العناصر التي تم إنقاذها إلى أعمال فنية تجريدية ومكانية متزايدة محولة .

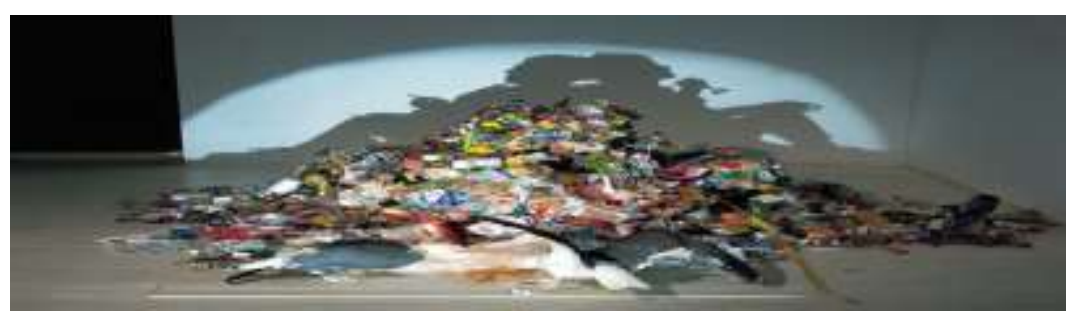

شكل (14) القهامة البيضاء (مع النوارس) (32)

العمل عبارة عن تجمعات قمامة وطائر النوارس، وجهاز عرض ضوئي متغير الأبعاد، وبإنعكاس تجمعات القمامة مع تسليط الضوء تتعكس علي الجدار لشخصين جالسين علي الأرض وفي يد أحداهما كأس .

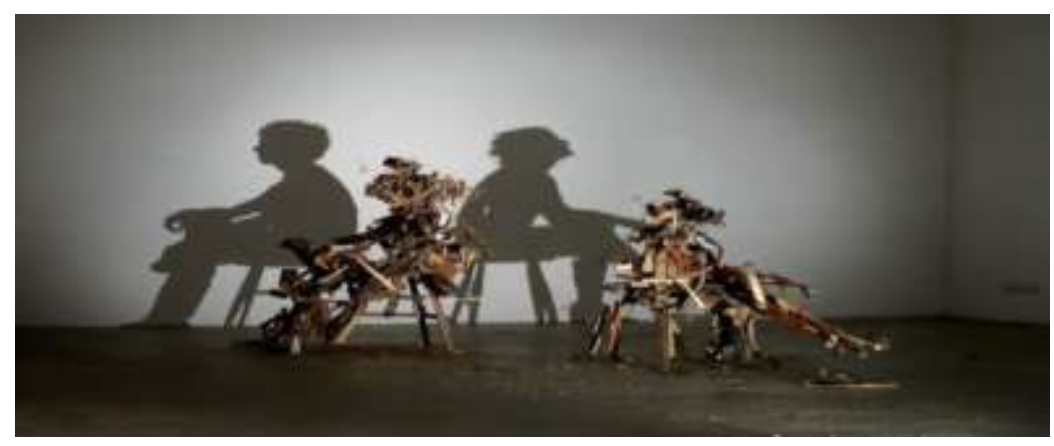

شكل (15) بعنوان "تقلبات المزاج البرية"(33)

العمل عبارة سلالم خشبية وجهاز عرض ضوئي و أبعاد متغيرة، وبإنعكاس تجمعات شرائح الأخشاب مع تسليط الضوء تتعكس علي الجدار لشخصين جالسين علي كرسي. ـ جماليات التحول للأنامورفوسيس القائم علي الإضاءة الحديثة :

"تيموثي نوبل (مو اليد 1966) وسوزان وبستر (مواليد 1967): هما فنانان بريطانيان يعملان الثنائي"،و هم مرتبطون بجيل ما بعد الحداثة Tim Noble . and Sue Webster /https://www.artworksforchange.org/portfolio/tim-noble-and-sue-webster ${ }^{32}$ 
أ.بإستخدم "الضوء والظل" بكل بساطة وجدارة ، ومصدرًا واحدًا للضوء تعطي أشكال لا تحصى لتحقيق الصورة المحولة كلما تغيرت زاوية الرؤية للعمل بشكل مختلف .

ب.فإنهم يعطوننا الأمل في أن البراعة وإعادة الإستخدام الإبداعي يمكن أن يضيء طريق التقدم البشري داخل المجال الفني



\section{الإطار العملي : تجربة تطبيقية" تنفيذ الفنانة زينب صبرة " (34) لرؤية جمالية مغايرة في مجال الأشغال الفنية في ضوء فن الأنامورفوسيس :}

تعد التجربة التطبيقية من تنفيذ الفنانة زينب صبرة فهي عبارة عن رؤية فنية متميزة في فن الأنامورفوسيس تستند إلي تقنية وأسلوب فني تؤهلة لإكتثاف الجمال في الفن كحقيقة متجددة ، ولأن العمل الفني يثتمل علي ما هو أكثر من مجرد الرؤية البصرية ، فهو مصدر للأفكار والمشاعر والمفاهيم وللوقوف علي ذلك يستند البحث إلي: أولاً : المفهوم الفلسفي للتحول : أخذ مصطلح التحول يثيع في الدراسات المتتوعة التخصص في كل مجالات الحياة ، وقد قامت هذه الدراسات بمحاولة رصده وتفسيره كنوع من الظواهر التي تصيب مفردات الوجود بالتغير والتبديل ، تبعاً لظروف محيطه تؤسس لهذا التحول وتحدد شكله وطبيعته ، سواء كان شكلاً ظاهرياً أو مادياً أو فكرياً " 35 ، إن المفهوم الفلسفي للتحول هو عملية تغيير في شكل البنية من حالة إلي حالة جديدة ، متحولة عن القيم الثابتة الناتجة عنها ، " ويشير بياجيه piaget إلي أن للبنية الفنية والأسلوبية نسق من التحولات ، ولها قوانينها الخاصة ، كما تعد نسقاً في مقابل الخصائص المميزة ، علماً بأن من شأن هذا النسق أن يظل قائماً ويزداد ثراء ، بفعل الدور الذي تقوم به تلك التحويلات نفسها ، دون أن يكون من شأن هذه التحويلات نفسها أن تخرج عن حدود

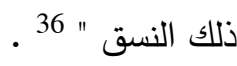
ثانياً : جماليات التحول :

و والتقنية 34 الفنانة زينب صبرة : عرفت الفنانة بالإرتقاء بمجال الأشغال الفنية ، حيث قدمت مداخل وحلول تمبيزت بـان بها من قوة التصميم

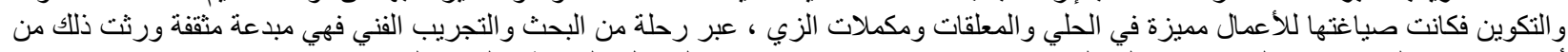

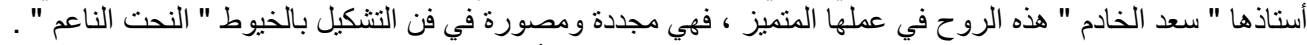

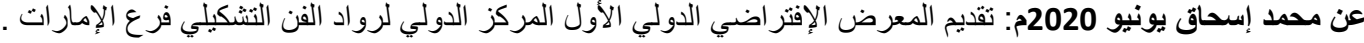

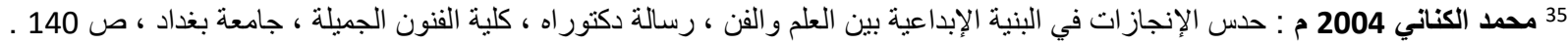

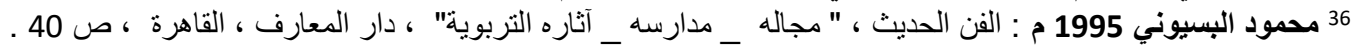


إن الجمال ليس بنقطة إبتداء وإنما هو نقطة الوصول ، إن الثئ يكون جميلاً فحسب إذا كان له سند من الحقيقة ، وتلك الحقيقة تعطينا نقطة إبتداء للوصول إلي أعلي درجات القيم الجمالية المحملة بالإتجاهات الفكرية التي تتسم بالمنطق والعقلانية . للتك يعد الثكل الجانب الجوهري في الفن وهو الجانب الأعلي ، والجانب الروحي يراه أفلاطون فكرة تسعي المادة إلي التغلغل فيها ، مما يتيح للفنان أن يبتكر أشكالاً ذات طابع حيوي ، فالفنان يسقط فكرة علي الواقع ، ليكتثف قانون الواقع مع الإيمان والرغبة في إعادة التثكيل لتقديم إبداع جديد ، فالفكرة هي مرجع للعقل في التجارب والخبرات ولغة الإفصاح بصورة جمالية وبدونها لا يكتمل بناء المشغولة الفنية .

فالتحول فكرة تتحول إلي تجربة وخبرة معرفية للفنان تؤسس نشاطه الإبداعي والفكري ومن ثم تتحول إلي تجربة شكلية لها كيانها ووجودها وفق أطر خاصة ، ومن بين هذه العمليات تجري عملية التحول والإتصال بين تجربة الفنان الفكرية وبين المتلقي عبر نظم دلالية سيميائية ، فالتجربة موقف فكري أما العمل الفني فهو الفكر المحقق بصورة فعلية من مادة معينة . كما يرتبط إدراك عملية التحول بصرياً بحركات العينيين " ويقصد بها تلك الحركات التي تجعل العينيين تتحركان في نفس إتجاه حركة المنبه وتتقسم إلي نوعين : حركات قفزية تعني الحركات السريعة ، والثانية حركات بتتبع وهي تلك الحركات لتعقب شئ معين "37 ، وينتج عن عملية التحول تغيرات ذات خصائص حركية ، فكل مرحلة تحول تمثل متغير علي المظهر الثكلي ، مما يحقق تأثيرات بالحركة الفعلية والإحساس بالعمق تتعكس علي الصفات التكوينية للثكل ونظامه ، فالحركة تعد أكبر مثيرات الإنتباه في المجال البصري خلال الفترات الزمنية المتتابعة ، فهي عبارة عن فعل ينطوي علي تغيير يقابله رد فعل علي هيئة حركة ملموسة وقد تكون داخلياً علي هيئة أحاسيس وإنفعالات ، فالحركة منها قد يحمل خط من الخطوط أو تقنية أو لون أو ملمس معني للحركة في العمل الفني ، كما تتحقق الرؤية من خلال الحركة داخل المنظومة الجمالية ومن مسار النقطة المحددة لأبعادها في • الفراغ

ثالثا: توصيف المشغولة الفنية :

أ_ التحليل الفني : عمل فني مجسم يعتمد علي الإيحاء لشكل العنصر الإنساني في الطبيعة ، حيث يمثل إمرأة بدوية تلتف بعباءتها ، ويلتف مرة أخري أطراف الثال الممتد من منطقة الرأس حولها ، ففكرة الإلتفاف بأوضاع وإتجاهات وملامس مختلفة هي 37 السيد علي السيد أحمد 2001 م : الإدر اك الحسي البصري السمعي ، مكتبة النهضة المصرية ، القاهرة ، ص 53 . 
الفكرة التي يدور حولها هذا العمل الفني ، كتعبير لوضع حركي معين ، ناتج من ثنايا الثثب الملبس ومكملاته وفقاً لإتجاه الحركة ، كما أن ظاهرة الإلتفاف لم تتبع فقط كأثر لفعل ما ( يلتف) ، ولكن توجد تلك الظاهرة في الطبيعة بالعديد من الكائنات الحية ، والتابعة من نظام تكوينها البنائي .

والمجسم المعبر عن الثكل هو عبارة عن معلجة أدائية لخامة الخيوط اللينة للوصول لدرجة من الصلابة لصياغة إنثائية متكاملة الرؤية يطلق عليها في فن التثكيل بالخيوط " النحت الناعم " soft Sculpture" .

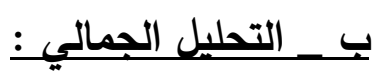

التحليل الجمالي للمشغولة الفنية المنفذة يقدم المعلومات المرئية للمشغولة التي تعد ترجمة مكتوبة لما تراه العين ، بإعتبار فن الأنامورفوسيس إتجاه فكري معاصر ومن الفنون الحديثة التي يمكن من خلالها التوصل إلي العديد من الأفكار الإبداعية المبتكرة ، والتي إعتمد عليها الفنانين في إنثاء أعمالهم الفنية والإستفادة منها كمرجعية إنثائية بنائية والكثف عن علاقات وتتظيمات وتتنيات مستحدثة تثري المشغولة الفنية التي يستند فيها الفنان علي التحليل الإنشائي الإبداعي • لذا يري البحث أن الفكرة الإنشائية البنائية للمشغولة الفنية موضوع الدراسة وفق جماليات التحول في ضوء فن الأنامورفوسيس فهو نتاج لعملية التنكير وإنتاج الفكر ومفردات الوجود بالتغير والتبديل ، كأساساً جوهرياً في مجال الأشغال الفنية والتصميم تلك التطور القائم علي أساس علمي بتقنية الأنامورفوسيس والتراث ويعد أول نموذج بهذه التقنية لفنانه مصرية ، حيث لم يتطرق أي فنان مصري لتلك التقنية من قبل ذلك ويتضح فيما يلي : أ ـ يستند العمل علي قانون الإنعكاس الأول . بـ_ يقدم العمل مجموعة متنوعة من الأنشطة البصرية والسمعية والحركية ، للتعبير عن أفكار المؤلف الإبداعية والمفاهمية والمهارة الفنية . يتضح الأنامورفوسيس داخل العمل من خلال إستخدام كلاً من الضوء والظل وبإنشاء كائنات مفردة أو متعددة ووضعها فيما يتعلق بمصدر ضوء واحد، وبالتالي يتألف العمل الفني الكامل من كل من المادة (الأجسام الصلبة) وغير المادية (الضوء أو الظل) لإحداث الوهم أثناء رؤية العمل من خلال الإضاءة، والأنوار والظلال أمثلة أصلية على صورة بصرية مشوهة تختبر تصوراتتا للواقع • " وفن الضوء هو شكل من أثكال الفنون التطبيقية يمثل الضوء فيها الوسيلة الرئيسية للتعبير، وهو شكل من 
أشكال الفن من خلال التلاعب بالضوء والألوان " 38. وتععيل الحركة أثناء نلاحظ ظهور ظل للعمل ولكن ظل غير مفهوم ، وبعد ربع لفة من دوران العمل نلاحظ أن الظل المنعكس من العمل علي الحائط للعمل مطبقأ في ذلك قانون الإنعكاس الأول " زاوية السقوط تساوي زاوية الإنعكاس " ، أصبح علي هيئة إمرأة تتظر إلي الأمام كما بالثكل السابق ، ومع إستمرار الدوران والحركة للعمل يصبح الظل المنعكس للعمل غير مفهوم ثانياً ثم بعد بعح اللفة الثانية نلاحظ تكون صورة واضحة للظل مرة آخري علي هيئة إمرأة مرة آخري ولكنها تنظر إلي الجهة اليمني ثم بعد ربع اللفة الثالثة تظهر المرأة وهي تنظر إلي الخلف ثم بعد ربع اللفة الرابعة تظهر المرأة وهي تتظر إلي جهة الثمال ـ ومن وجهة النظر بالبحث أن من العوامل الهامة عند إستخدام الضوء كعنصر من عناصر التشكيل ، إنه يعطينا مجالاً واسعاً للإستفادة منه بالتشكيل والتحول ، خصوصاً وأن الضوء لا يبدو واضحاً ومؤثراً وتكويني للشكل إلا بإنعكاسه علي سطح عاكس ، كما هو بالعمل المنفذ . ج _ يعتمد العمل علي الرسم المنظوري :

تحليل العمل المنفذ نظراً إلي زواياها ، ومنحنياتها التي تتغير إذا تغيرت زاوية الثخص لها من أبعاد مختلفة والذي يسمي بالرسم المنظوري بطريقة الأنامورفوسيس ، وقد بنيت التحاليل الفنية للشكل بأن كلاً منها تعبر عن شئ معين إذا نظرنا للعمل من زاوية معينة تمثل الحركة المستمرة ، والجزء أعلي العمل من الإضاءة تدفع الثخص بالنظر إلي أعلي .

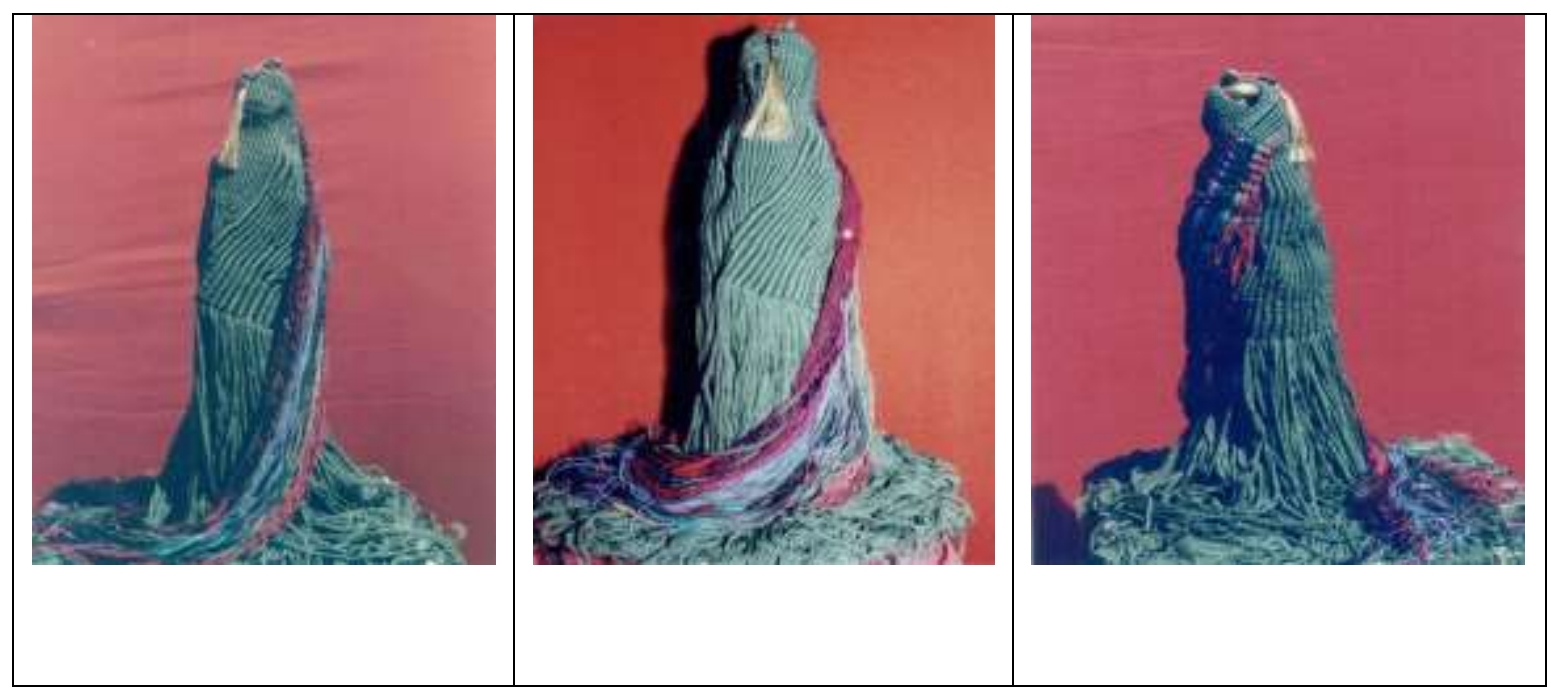

شكل (16) يوضح زاويا رؤيا مختلفة للعمل الفني المنفذ بالتجربة التطبيقية

$$
\text { تنفيذ الفنانة " المؤلف " : أ. د / زينب صبره }
$$


• مرفق تصوير العمل الفني من خلال فيديو (1) بالضوء والصوت والحركة الفعلية مستند علي المفهوم الرياضي والنظرية العلمية للأنامورفوسيس .

\section{رابعاً : معالجة نتائج البحث في ضوء الدراسة النظرية والتحليلية لإستخلاص القيم الجمالية في التجربة}

$$
\begin{aligned}
& \text { : التطبيقية } \\
& \text { 1_ـ إخضاع الرؤية الفنية وفقاً لحسابات رياضية . } \\
& \text { 2__تحقيق القيم الحسية الجمالية ، تحول أجهزة الإحساس إلي مجالات للإمتاع الجمالي • } \\
& \text { 3_ الإستتاد إلي القيم التعبيرية والثكلية يقوي الإحساس بالبهجة الجمالية . }
\end{aligned}
$$

4_ الإستناد إلي العنصر الآدمي بشكل الوحدة العضوية للمنتج الإبداعي بما تحمله لامن الطاقات الثكلية واللونية ، تكسب العمل الفني معني رمزي يؤثر جماليات في وجدان المشاهد . 5_ تحقيق الإستمتاع بالمعاني الرمزية بفضل التفاعل والمشاركة العاطفية بين المشاهد والعمل الفني •

1__تعتبر جماليات فن الأنامورفوسيس إمتداداً متطوراً لأساليب فنية عديدة ظهرت في فترات زمنية مختلفة . 2__توظيف العلوم الرياضية في الفنون التشكيلية أبدع رؤية تشكيلية ونظرية جديدة . 3_ فتح آفاق مثالية للرؤية الجمالية وراء المفاهيم الجديدة لدمج الفن والعلم والتكنولوجيا . 4_ يتميز فن الأنامورفوسيس في أعمال الفنانين المعاصرين برؤية جمالية مغايرة للفن تتفق مع فلسفته وثقافته . 5ـ تؤثر جماليات الأنامورفوسيس وتتنياته المتفردة في تغيير مفاهيم التلقي • 6_ إخضاع الرؤية الفنية للملاحظة والتجريب من خلال متعة الفن البصري المتحول بأن ننظر بدلأ من أن تتوقع • 7_ تعد جماليات التحول من فن الأنامورفوسيس مصدراً جديداً لتدريس مجالي الأشغال الفنية والتصميم ـ التوصيات : 
"يوصي المؤلفون بالمزيد من الدراسات والتطبيقات لفن الأنامورفوسيس وأنماطه المتعددة .

"يوصي المؤلفون بتشجيع وتحفيز الفنانين والباحثين في الفنون علي إجراء بحوث مشتركة في مجال

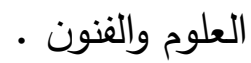

"يوصي المؤلفون بالمزيد من الدراسات التي تركز علي الإتجاهات الفنية الحديثة .

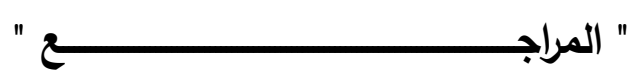

1. السيد علي السيد أحمد 2001 م : الإدراك الحسي البصري السمعي ، مكتبة النهضة المصرية ، القاهرة . 2. محمود البسيوني 1983م : "الفن في القرن العشرين" ، دار المعارف ، القاهرة .

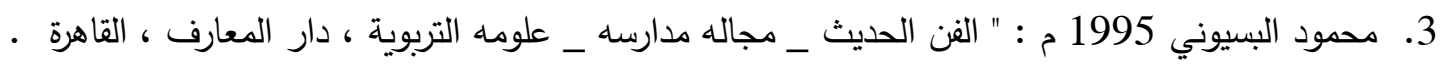

ثانياً : المراجع الأجنبية :

1_Sánchez-Reyes, Javier; Chacón, Jesús M. (August 1, 2016). "Anamorphic Free-Form Deformation". Computer Aided Geometric Design. 46: 30-42.

doi:10.1016/j.cagd.2016.06.002 .

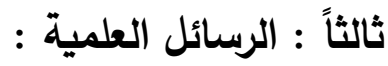

1_ محمد الكناني 2004 م : حدس الإنجازات في البنية الإبداعية بين العلم والفن ، رسالة دكتوراه ، كلية الفنون الجميلة ، جامعة بغداد.

رابعاً : المواقع الإكترونية :

1. https://mbnart.wordpress.com/83-2 I

2. http://nasser-karim.blogspot.com/2014/07/

3. figuresambigues.free.fr/ArticlesTheorie/5-ambiguorientations.html\#axzz6mdCShxvV

4. https://en.wikipedia.org/wiki/Jonty Hurwitz

5. https://www.boredpanda.com/anamorphic-sculptures-jontyhurwitz/?utm source=google\&utm medium=organic\&utm campaign=organic

6. https://twistedsifter.com/2014/08/anamorphic-hand-sculpture-by-jonty-hurwitz/

7. https://en.wikipedia.org/wiki/Trompe-1\%27\%C5\%93il

8. https://www.widewalls.ch/artist/jonty-hurwitz/ 
9. https://blogs.mathworks.com/community/2013/07/09/anamorphic-3d-printing/

10. https://www.antoniosiber.org/marko mareljas anamorphosis en.html

11. https://www.yelp.fr/biz photos/art-up-lille?select=r7SiytGVZSR9yF HjDAyqA

12. https://mymodernmet.com/bernard-pras-ferdinand-cheval/

13. http://thomasmedicus.at/intercella/

14. http://thomasmedicus.at/expo2020/

15. https://link.springer.com/article/10.1007/s00004-014-0225-5

16. http://kumiyamashita.com/light-shadow

17. https://www.artworksforchange.org/portfolio/tim-noble-and-sue-webster/

18.

https://ar.wikipedia.org/wiki/\%D9\%81\%D9\%86 \%D8\%A7\%D9\%84\%D8\%B6\%D9\% 88\%D8\%A1

19. 